\title{
Confidencialidade e sigilo profissional em estudos sobre caça
}

\author{
Luciano Martins Verdade ${ }^{1,3}$ \& Cristiana Simão Seixas ${ }^{2}$ \\ ${ }^{1}$ Laboratório de Ecologia Isotópica, Centro de Energia Nuclear na Agricultura - CENA, \\ Universidade de São Paulo - USP, CP 96, CEP 13416-000, Piracicaba, SP, Brasil \\ ${ }^{2}$ Núcleo de Estudos e Pesquisas Ambientais - NEPAM, Universidade Estadual de Campinas - UNICAMP, \\ Campinas, SP, Brasil \\ ${ }^{3}$ Autor para correspondência: Luciano Martins Verdade, e-mail: Imverdade@usp.br
}

VERDADE, L.M. \& SEIXAS, C.S. Confidentiality and professional secrecy in studies about hunting. Biota Neotrop. 13(1): http://www.biotaneotropica.org.br/v13n1/en/abstract?point-of-view+bn00113012013

Abstract: In Brazil information about illegal hunting activities is rarely pursued because of a lack of legal mechanisms of confidentiality and professional secrecy that would assure legal rights to the researcher. Without such mechanisms, data collection on illegal hunting can be considered a felony or compliancy where the researcher can suffer the same legal penalties as the illegal hunters themselves. Such procedure is questionable on philosophical, legal and technical grounds. The biological sustainability of hunting - legal or illegal - can only be evaluated by research involving data collection. In order to solve this problem, biologists should have legal rights concerning confidentiality and professional secrecy in research on illegal hunting in Brazil. Lawyers, medical doctors and social scientists already have such legal protection in analogous situations.

Keywords: ethics in research, legal rights, hunting pressure, biologists, illegal hunting.

VERDADE, L.M. \& SEIXAS, C.S. Confidencialidade e sigilo profissional em estudos sobre caça. Biota Neotrop. 13(1): http://www.biotaneotropica.org.br/v13n1/pt/abstract?point-of-view+bn00113012013

Resumo: No Brasil informações sobre atividades ligadas à caça ilegal dificilmente são levantadas em função da falta de um mecanismo legal de confidencialidade e sigilo profissional que assegure ao pesquisador os princípios do direito. Sem isso, tal coleta de dados é passível de ser considerada crime ou cumplicidade criminosa, podendo o pesquisador sofrer as mesmas penalidades legais que os próprios caçadores. Este procedimento é questionável do ponto de vista filosófico, legal e técnico. A sustentabilidade biológica da caça, legal ou ilegal, só poderá ser avaliada por meio de pesquisas sobre o tema, envolvendo coleta de dados. A fim de mudar tal cenário, é necessário que biólogos tenham o direito ao sigilo profissional e à confidencialidade em pesquisas sobre a caça no Brasil. Advogados, médicos e sociólogos já contam com tais precedentes legais em situações análogas.

Palavras-chave: ética na pesquisa, direito, pressão de caça, biólogos, caça ilegal. 
A caça foi atividade legal e regulamentada no Brasil entre 1934 e 1967 [Código de Caça e Pesca (1934); Código da Caça (1943)]. A partir de 1967, a Lei de Proteção à Fauna (Lei 5.197), proibiu a caça com finalidade profissional, regulamentou a caça esportiva, mas não considerou a caça de subsistência. As infrações a esta Lei eram consideradas contravenções penais, delitos mais brandos, puníveis com multas e prisão de até um ano para réus não primários. Em 1988, a caça tornou-se um crime inafiançável com a Lei Federal $\mathrm{n}^{\circ} 7653 / 88$. Somente 10 anos depois, a Lei de Crimes Ambientais (Lei 9.605/1998) descriminalizou o abate de animais silvestres para saciar a fome do agente ou de sua família, legalizando assim a caça de subsistência. Entretanto, ela não estabeleceu mecanismos de controle para essa atividade (Wallauer 2003).

A caça de subsistência é atividade praticada em todas as regiões do país, principalmente, mas não exclusivamente, por populações indígenas e as chamadas populações tradicionais. O uso sustentável da fauna silvestre por populações tradicionais ocorre há gerações em muitas regiões do planeta, por meio de regras de uso e acesso aos recursos, baseadas no conhecimento ecológico local (Johannes 2002, Berkes 2009).

O conhecimento ecológico que caçadores experientes possuem sobre a história natural dos animais caçados pode ser de grande valia para o manejo e conservação da fauna silvestre, bem como para complementar o conhecimento científico sobre essa fauna (Berkes 1999, Berkes et al. 2000, Huntington 2000). Ademais, dados quantitativos sobre caça podem fornecer informações valiosas sobre padrões históricos de distribuição geográfica e abundância da fauna silvestre, além da estrutura trófica de uma comunidade, da demografia de espécies cinegéticas e, obviamente, da própria pressão de caça (Caughley 1977, Caughley \& Sinclair 1994, Cullen Junior et al. 2000, Sinclair et al. 2006).

No Brasil, informações provenientes de caçadores, dificilmente são levantadas em função da falta de um mecanismo legal de confidencialidade e sigilo profissional que assegure ao processo os princípios do direito. Sem isso, tal coleta de dados é passível de ser considerada crime ou cumplicidade criminosa (Machado 2010), podendo o pesquisador sofrer as mesmas penalidades legais que os próprios caçadores. Este procedimento é questionável sob pontos de vista filosófico, legal e técnico.

Do ponto de vista filosófico, tal procedimento levanta questões ligadas à ética aplicada (Haldane 2007) e à ética ambiental (Rolston 2007). O levantamento de dados ecológicos e etnoecológicos (i.e., conhecimento ecológico local) relativos à atividade da caça ilegal implica apenas em sua avaliação, enquanto processo antrópico que pode afetar a biodiversidade, e não no processo em si ou em seu estímulo ou conivência com atividade ilícita. São paralelos a isto, por exemplo, a ação do médico que trabalha com pacientes que consumam narcóticos, do sociólogo que trabalha com violência doméstica ou o advogado que defende um réu.

Do ponto de vista legal, nas circunstâncias acima, o médico é respaldado pelo Código de Ética Médica (Conselho... 2009), o sociólogo é respaldado pelo Código de Ética do Sociólogo (Carvalho \& Prá 1997) e o advogado é respaldado pelo Código de Ética e Disciplina da Ordem dos Advogados do Brasil (Batochio \& Carvalhosa 1995). O biólogo que levanta dados sobre caça deveria, da mesma forma, ser amparado pelo Código de Ética do Profissional Biólogo (Conselho... 2011). Para isto, o Conselho Federal de Biologia deveria inserir em seu código de ética um artigo sobre o tema. Projetos de pesquisa sobre caça teriam que passar pela comissão de ética das instituições a que pertençam seus coordenadores, a exemplo do que já ocorre com qualquer pesquisa envolvendo manipulação de animais ou ética humana.
Do ponto de vista técnico, a caça ou coleta é uma das alternativas de manejo da vida silvestre (Leopold 1933, Caughley 1994, Thompson 1997), podendo ser biologicamente sustentável, desde que a parcela retirada da população animal não exceda sua taxa de recrutamento (Connely et al. 2005). Hoje, no Brasil, com exceção de clubes de caça na região sul e de alguns programas de manejo em Unidades de Conservação de Uso Sustentável (e.g., jacaré-açu, Melanosuchus níger, em Reservas de Desenvolvimento Sustentável da Amazônia, Thorbjarnarson 2010), a atividade de caça (seja legal de subsistência ou ilegal) não é manejada, podendo ter sérias conseqüências para a conservação das espécies caçadas e sua própria sustentabilidade. Ademais, a restrição da atividade de caça pela legislação tem levado a um abandono de práticas locais de uso e manejo da fauna silvestre por populações tradicionais, resultando na ruptura da transmissão desse conhecimento ecológico local para as novas gerações. $\mathrm{O}$ acesso a este conhecimento é por isso urgente e depende de estudos etnoecológicos com grupos de caçadores experientes; daí a relevância de se resguardar o direito dos pesquisadores de acessar este conhecimento e, ao mesmo tempo, garantir seu sigilo profissional.

A crítica ao excessivo conservadorismo existente no Brasil sobre o tema sugere que a proibição completa à caça seja socialmente excludente (Robinson \& Redford 1991, Moulton \& Sanderson 1997) e economicamente inviável por deixar de valorar a biodiversidade (Magnusson 1993, Verdade 2004, Mourão et al. 2006). De qualquer forma, a sustentabilidade biológica da caça, legal ou ilegal, só poderá ser avaliada por meio de pesquisas sobre o tema. Para isto é necessário que biólogos tenham o direito ao sigilo profissional e à confidencialidade em pesquisas sobre a caça no Brasil.

\section{Referências Bibliográficas}

BATOCHIO, J.R. \& CARVALHOSA, M. 1995. Código de Ética e Disciplina da OAB. 11p. http://www.eticaempresarial.com.br/imagens_arquivos/ artigos/File/Eticaenegocios/CodEticaDisciplina\%20OAB.pdf. (último acesso em 20/01/2011).

BERKES, F. 1999. Sacred Ecology: Traditional Ecological Knowledge and Resource Management. Taylor and Francis. Philadelphia and London, 209p.

BERKES, F. 2009. Community conserved areas: policy issues in historic and contemporary context. Conserv Letter. 2(1):19-24.

BERKES, F.; COLDING, J. \& FOLKE, C. 2000. Rediscovery of traditional ecological knowledge as adaptive management. Ecol. Appl. 10(5):1251-1262. http://dx.doi.org/10.1890/10510761(2000)010[1251:ROTEKA]2.0.CO;2

CARVALHO, L.M.G.X. \& PRÁ, A. 1997. Código de Ética do Sociólogo. 7p. http://www.dhnet.org.br/direitos/codetica/codetica_brasil/sociolg.html. (último acesso em 20/01/2011).

CAUGHLEY, G. 1977. Analysis of vertebrate Populations. John Wiley \& Sons, New York, 234p.

CAUGHLEY G. 1994. Directions in conservation biology. J. Anim. Ecol. 63:215-44. http://dx.doi.org/10.2307/5542

CAUGHLEY, G. \& SINCLAIR, A.R.E. 1994. Wildlife ecology and management. Blackwell, Boston, 334p. PMid:8088727.

CONNELY, J.W., GAMMONLEY, J.H. \& PEEK, J.M. 2005. Harvest management. In Techniques for Wildlife Investigations and Management (C.E. Braun, ed.). 6th ed. The Wildlife Society, Bethesda, Maryland, p.658-690.

CONSElHo FEDERAL DE BIOLOGIA - CFBio. 2011. Código de Ética do Profissional Biólogo. 9 p. http://www.cfbio.gov.br/conteudo. php?pagina=Codigo_de_Etica. (último acesso em 20/01/2011). 
CONSELHO REGIONAL DE MEDICINA DO ESTADO DE SÃO PAULO - CRM/SP. 2009. Código de Ética Médica: Código de Processo Ético Profissional, Conselhos de Medicina, Direitos dos Pacientes. Conselho Regional de Medicina do Estado de São Paulo, São Paulo, 96 p.

CULLEN JUNIOR, L.; BODMER, R.E. \& PÁDUA, C.V. 2000. Effects of hunting in habitat fragments of the Atlantic forests, Brazil. Biol. Conserv. 95:49-56. http://dx.doi.org/10.1016/S0006-3207(00)00011-2

HALDANE, J. 2007. Ética aplicada. In Compêndio de Filosofia (N. Bunnin \& Tsui-James E.P., org.). Edições Loyola, São Paulo, p.529-538.

HUNTINGTON, H.P. 2000. Using Traditional Ecological Knowledge in Science: Methods and applications. Ecol. Appl. 10 (5):1270-1274. http:// dx.doi.org/10.1890/1051-0761(2000)010[1270:UTEKIS]2.0.CO;2

JOHANNES, R.E. 2002. The renaissance of community-based marine resource management in Oceania. Ann. Rev. Ecolog. Syst. 33:317-340 http://dx.doi.org/10.1146/annurev.ecolsys.33.010802.150524

LEOPOLD, A. 1933. Game Management. The University of Wisconsin Press, Madison, Wisconsin, 481p.

MACHADO, P.A.L. 2010. Direito Ambiental Brasileiro. 18. ed. Malheiros Editores, São Paulo, 1177p.

MAGNUSSON, W.E. 1993. Manejo de vida silvestre na Amazônia. In: Bases Científicas para Estratégias de Preservação e Desenvolvimento da Amazônia (E.J.G. Ferreira, G.M. Santos \& L.M. Leão, eds.). Instituto Nacional de Pesquisas da Amazônia, Manaus, v.2, p.313-318.

MOULTON, M.P. \& SANDERSON, J. 1997. Wildlife Issues in a Changing World. St. Lucie Press. Delray Beach, Florida, 352p.
MOURÃO, G, RIBAS, C. \& MAGNUSSON, W. 2006. Manejo de fauna silvestre no Brasil. In: Biologia da Conservação: Essências. (C.F.D.Rocha, H.G. Bergallo, M. Van Sluys \& M.A.S. Alves, eds.). RiMa Editora, São Carlos, p.459-477.

ROBINSON, J.G. \& REDFORD, K.H. 1991. The use and conservation of wildlife. In Neotropical Wildlife Use and Conservation (J.G. Robinson, \& K.H. Redford, eds.). The University of Chicago Press, Chicago, p.3-5. PMid:1989435.

ROLSTON III, H. 2007. Ética ambiental. In Compêndio de Filosofia. (N. Bunnin, \& E.P. Tsui-James, org.). Edições Loyola, São Paulo, p.557-571.

SINCLAIR, A.R.E., FRYXELL, J.M. \& CAUGHLEY, G. 2006. Wildlife Ecology and Management. 2nd ed. Blackwell Scientific Publications, Malden, 469p.

THOMPSON, E.P. 1997. Senhores \& Caçadores. Editora Paz e terra, São Paulo, 432p.

THORBJARNARSON, J.B. 2010. Black Caiman Melanosuchus niger. In Crocodiles. Status Survey and Conservation Action Plan (S.C. Manolis $\&$ Stevenson C., eds.). 3rd ed. Crocodile Specialist Group, SSC, IUCN, Darwin, Australia, p.29-39.

VERDADE, L.M. 2004. A exploração da fauna silvestre no Brasil: jacarés, sistemas e recursos humanos. Biota Neotrop. 4(2):1-12.

WALLAUER, J.P. 2003. Geografia da Gestão de Fauna no Brasil: em busca de alternativas. Tese de doutorado, Universidade Federal de Santa Catarina, Florianópolis. PMid:12910468. 
